\section{Barbara Mazur}

Politechnika Lubelska, Wydział

Zarządzania, Polska

bmazur@pollub.pl

\section{Marta Mazur-Małek}

University of Tartu Parnu College, Estonia

Mazur.malek@yahoo.com

\title{
Towards Corporate Wellness: Health Culture and Wellness Programs
}

Abstract: The aim of the article is to present wellness programs as means leading to the creation of culture of health in organizations. The notion of culture of health is becoming increasingly important for companies as statistics show that the number of health-related work problems is steadily increasing. As a result, labor costs are systematically increasing. To tackle this problem, companies began to introduce health and wellness programs to improve the psychophysical health of their employees. The article includes an overview of the concept of health-promoting company culture. It also identifies factors determining its success among employees, defines factors that limit employee participation and presents good practices for disease prevention through employee-oriented programs. This article is based on a literature review, including both: literature and statistical data available in official data bases. In many cases, research confirms the usefulness of wellness programs in the process of building a corporate culture of health. It also shows factors limiting the usability of such programs, which leads to companies being able to develop and improve.

Key words: wellness programs, health culture, organizations, good practices 


\section{Introduction}

Nowadays in the organization's world much importance is given to the notion of overall health and wellbeing. Sedentary lifestyles and bad health habits contribute significantly to a more unwell population worldwide (Malleret, 2016 a). Malleret (2017b \& 2017 d) points to the negative impact of technology, work burnout, and depression on health globally. Global Wellness Institute's industry report from 2016 also claims that the World's workers are "increasingly unwell". The report estimates the cost of employees' unwellness, which embraces the medical expenses and the loss of productivity, at a staggering $10-15 \%$ of the global economic output. Also, the report assumes the cost of work-related diseases and injuries, health problems caused by work stress, chronic diseases and employee disengagement in work in the United States to about $12 \%$ of the country's GDP (The Future of Wellness at Work (Rep.), Global Wellness Institute, 2016, p. i). OECD (2016) data demonstrates the rising cost of healthcare in many countries. According to OECD statistics (Health expenditure and financing, Non-Medical Determinants of Health, and Health Status - Absence from Work Due to Illness) the macro trends of growing obesity and healthcare costs as well as the increasing number of missed workdays due to illnesses are gaining impact annually.

During the Global Wellness Summit in 2016, the macroeconomic factors influencing the health and wellness scene globally were comprehensively discussed. The rising inequality in the World, inflexible political regulations, economic insecurity, the global problem of loneliness and chronic diseases on the grow while the overall population gets older were stated among the most influential ones. It was also argued that the ways companies spend their money are not contributing to the improvement of employee wellness (Malleret, 2016 a). Additionally, there appeared suggestions that the workplace is the most suitable place to start tackling the problems of health (Purcell, 2016). It is because the workplace is the single biggest people-gathering 
place daily. As a universal phenomenon, worksite wellness directly influences the employers and employees and indirectly employee families, governments, and individuals.

The article includes an overview of the concept of health-promoting company culture. It also identifies factors determining its success among employees, defines factors that limit employee participation and presents good practices for disease prevention through employee-oriented programs. This article is based on a literature review, including both: literature and statistical data available in official data bases. In many cases, research confirms the usefulness of wellness programs in the process of building a corporate culture of health. It also shows factors limiting the usability of such programs, which leads to companies being able to develop and improve.

\section{Corporate Health Culture}

According to the Oxford dictionary health is "the state of being free from illness or injury". It is a very basic definition and pictures the health in relation to illness solely. Health is a complex and highly individual concept, it cannot be defined only by the occurrence of a disease, injury, or illness, Health can also be understood in a positive way, as argued by Herzlich (1973, as cited in Dodge, Daly, Huyton \& Sanders, 2012, p. 224) when one is fully aware of its presence and can, therefore, function freely.

Offered by The World Health Organization (WHO) understanding of health is more comprehensive. According to the WHO "health is a state of complete physical, mental, and social well-being and not merely the absence of disease or infirmity" (Preamble to the Constitution of the World Health Organization, 1948).

The ancient Latin term 'culture' was originally applied to the human-specific activity of agriculture. The authorship of the new use of the term is attributed to the Roman orator, politician and statesman Cicero, who first used the term 'cultura animi' (cultivation of the mind). 
Since then, the term culture has been associated with human activities aimed at perfecting, nurturing, and education. The modern use of the term 'culture' was observed for the first time in 1688, when S. Pufendorf in one of his works used the words 'cultura' and 'cultura animi' indicating any manmade inventions. This term embraced among other social institutions, language, morality, customs and dress. Later the term was more often used by philosophers and subsequently by representatives of the social sciences. The most frequently quoted definition of culture was formulated in the nineteenth century by E. Tylor, who described culture as a complex and interrelated set of elements including knowledge, beliefs and values, art, law, morals and moral principles and all other types of skills and habits acquired by a human being as a member of a particular community (Tylor, 1891). This definition initiated the definitions of culture, which enabled its inclusion in the area of a variety of social skills and habits, under the condition of their learned and social character.

Corporate culture is the pervasive values, beliefs and attitudes that characterize a company and guide its practices. Sharing values and beliefs creates a culture also in the corporate environment (Sinek, 2011). When the values and beliefs are authentically at the core of the business, the organization starts to grow. Sinek (2011) also claims that being a part of an authentic culture (be it corporate culture) and being able to help others within the community is the source of job satisfaction and life fulfilment.

One is inclined to say that culture of health is an element based on basic foundations of the human (emotional, managerial) engagement and a structure which facilitates healthy choices.

It is believed that "best companies create a culture of health" (Mirabito as cited in Carlson, 2014, p. 23). That culture of health can be identified by an environment and policies encouraging making healthy choices. Those choices will lead to an increased health and less absenteeism at work (Nash, 2015). Serxner (2017) suggests that implementing a worksite wellness program can help to establish a culture of health. In a work environment, the 
employee is unconsciously influenced on decision-making. In an environment that encourages healthy choices, the employee is more likely to make them, author claims. Additionally, Dailey \& Zhu (2016) have found that participation in a worksite wellness program (WWP) mediated the relationship between personal health and organizational identities. A WWP served as an identity bridge, easing the employee into the work environment.

Nevertheless, creating and changing corporate culture is a long process. Therefore, organizations should not expect an immediate Return On Investment (ROI) from wellness programs (Nash, 2015).

\section{Worksite Wellness Programs: Key Enablers}

In recent years, factors allowing for a more effective implementation of wellness programs have been the topic of academic interest. Mellor \& Webster (2013) identified key enablers and challenges when introducing a comprehensive wellness approach in an organization. The key enablers turned out to be: leadership engagement and support, resources dedicated to the mission, stakeholders' involvement and intensive communication. Furthermore, research was carried out on the way in which transformational leaders influenced employee psychological health by Walsh, Dupre, and Arnold (2014). The authors assumed that transformational leadership is understood as "encouraging performance beyond expectations" (Walsh, Dupre, and Arnold, 2014, p. 163). The results of the study show that two notions mediate outstanding performance - empowerment and perception of justice. Transformational leaders encourage employees to perform beyond what is expected through fairness and employee empowerment. This translates into the individual's perception of the company and self. Therefore, it can be beneficial for the company performance as well as for the individual's wellbeing.

During the Global Wellness Summit in 2016 it was assumed that about $80 \%$ of corporate income after tax is dedicated to cover medical expenses, while only less than $3 \%$ contributes to the prevention budget. It seems that 
companies do not spend enough to prevent the work related diseases and relatively unproportionable too much to cure them. Therefore, given this data, wellness should be an essential priority for both - the private and public sectors (Malleret, 2016a). Prevention of diseases will cost less than the treatment, especially among aging societies (Bens, 2017), so among most of the developed countries.

The issue of co-worker relations and job satisfaction was researched by Birgbom \& Kinnunen (2014). They, however, focused on the relationships in a multinational environment - especially with immigrants in the workforce. The results of the research suggest that all co-worker interaction positively influences the well-being of an employee. However, according to research results, a special kind of interaction - between an immigrant worker and a host national worker - seemed especially beneficial regarding job satisfaction. In the light of the research, perhaps worksite wellness programs would benefit from tailoring to the specific national culture and political situation of the company's setting, ensuring the right models for the particular culture, and paying attention to international and intercultural relations for the wellbeing of the employee.

There are 250000 preventable deaths in the United States annually happening because the health providers are not adequately cared for (Sinek, 2012). Sinek (2012) suggests that state hospitals are run like businesses while their core goal is to provide healthcare and not necessarily make the most money possible. He states that doctors who are taken care of well are much more likely to do a better job and therefore suggests a solution to decrease the number of preventable deaths in the U.S. The example of medical doctors is so powerful due to the meaningfulness of the work done. Lavine (2012) introduces the concept of Corporate Social Performance (CSP) and its relationship to work meaningfulness. According to the author, CSP is comprised of corporate citizenship, social responsibility, and sustainability (p. 53). The results of Lavine's study suggest that workers of companies with a higher commitment to corporate social performance have ascribed 
more meaningfulness to the jobs. This was because higher CSP allowed for a more fitting alignment with employee values; thus, increasing the perceived value of the job carried out. Additionally, the report regarding company caring suggests that in a group perceived as caring, the employees are more likely to feel employer's support, be more honest and open, as well as say that their managers and leaders lead by example (Everyday Health INC., \& Global Wellness Institute, 2016, p. 11).

\section{Worksite Wellness Programs: Key Challenges}

There are numerous studies on how the management can enhance the value of work and make the workplace a healthier one for the employees. However, there are also studies showing the opposite relation. Among the most popular ones are those concerned with corporate psychopaths, toxic leadership, or the employee attitude to health as a very personal matter.

Boddy (2013) reviews corporate psychopaths and their influence on employee wellbeing. Not surprisingly, the results indicate that corporate psychopaths can significantly affect the well-being of other employees. What is more, counterproductive work behavior and bullying are much more probable when a corporate psychopath constitutes a part of the work team.

Mehta \& Maheshwari (2013) also studied negative influences in the workplace. Toxic leadership was described by them with the following behaviors: abusiveness, promoting inequity, indecisiveness, divisiveness and lack of integrity. Their study proved that toxic leadership significantly decreases job satisfaction levels and organization commitment among employees. Mehta \& Maheshwari (2013) make the point that companies should not only identify toxic leaders but take action against them.

According to Robroek et al. (2011) who investigated the reasons for non-participation in a worksite wellness program (WWP), some employees did not participate in a WWP because they wanted to arrange it themselves; some did not wish their private and professional lives to interfere; for some 
employees intervention in their health was a violation of privacy. Robroek et al. (2011) suggests that the way WWP is communicated to the employee might influence the participation rates significantly. A WWP should not create any moral issues among the employees. Toker, Heaney \& Ein-Gar (2014) also investigated barriers to participation in WWPs. According to the results of their research, there were some groups of employees much less likely to participate than others. Those groups were: older employees, men, blue-collar workers, employees with a worse than optimal health status, employees who perceived their workplace as weakly committed to employee health. The authors suggest that enhancing the participation rates might be achieved by building a WWP according to the needs of the non-participative groups.

Zheng et al. (2015) conducted research which shows that monetary and non-monetary based provision of corporate employee wellbeing programs had no direct association with wellbeing. The key to employee wellbeing, authors seem to suggest, is the employee's personal life coping strategies. What companies can do for the employees to increase their wellbeing, then, is to help them develop and enhance individual coping strategies. That way, indirectly, wellbeing programs can affect the employee.

Mellor \& Webster (2013) identified the general key challenges in introducing a wellness program at work, which were: making the program a comprehensive whole, finding the right proportion between occupational and lifestyle risks and willingness and ability of management to monitor and support health-related issues, and a target-driven corporate culture.

\section{Worksite Wellness Program Evaluation}

Evaluating the effectiveness of a wellness program is a key issue for organizations establishing a corporate health culture (Mazur, Mazur-Małek, 2017). Knowing the factors affecting the evaluation of these programs is important for companies. That is why many researchers have been trying to determine them. 
Keller et al. (2009) examined whether the size of the company and employees' gender influence the impact of the worksite wellness program. The program effectiveness was measured based on six criteria: fitness, nutrition and weight, blood pressure and stress, substance abuse, smoking, and safety (Keller et al., 2009, p. 295). Additionally, the employees' gender and the size of the company were taken into consideration. The effectiveness study was based on the percentage of company's cost reduction regarding expenses on employee health. The results have shown a significant decrease in the expenditure, deeming the programs effective. Depending on the criteria of the investigation, some programs seemed more efficient among bigger companies and some among smaller. Similar results related to the employee gender (Keller et al., 2009, p. 300). Some programs worked better with female employees, and some with male. This study, too, shows that choosing a worksite wellness program tailored for the size and target group within the company matters for its overall effectiveness.

It was also investigated how health of employees improved after taking part in a worksite wellness program (Elia \& Rouse, 2016). In comparison with the control group (non-participants of the WWP) employees from the program reported significantly higher health gains. There was an increase in self-reported physical activity, drinking water, improved nutrition, lost weight and more energy. Elia \& Rouse (2016) have also looked at the perceived barriers to gaining health. Those decreased in the duration of the program. There were fewer voices stating lack of time or motivation, during and after participation in a WWP. Authors conclude that a successful WWP includes managerial engagement, encouraging a culture of health, tailored communication, and program evaluation. There is also research on the effects of worksite wellness programs focused on one particular health issue. For instance, Edmunds, Stephenson \& Clow (2013) describe the positive effect of a physical activity intervention among employees and Chen et al. (2016) characterize the positive effect of smoking counselling interventions. 


\section{Worksite Wellness: Current Practices}

Whilst wellness programs are gaining popularity, it is not yet a common phenomenon. It is therefore advisable to promote good practice in this area to facilitate benchmarking.

Cappelli (2014) writes about the shift in the worksite health world - from a more paternalistic model towards a market-based approach. Cappelli (2014) compares two giant global companies - Google and Walmart regarding health-related employee benefits. While Walmart was cutting employee benefits for some, Google was adding them. The shift from an approach where the employer is responsible for employee health (treating employees more or less equally in that aspect) towards one where the benefits are a demonstration of employee's value to the company. Walmart was cutting its benefits for the employees who were employed in lower level positions and those employed only part-time; showing that the value of those employees is decreasing. Google, on the other hand, was adding benefits for its employees as to demonstrate how vital they are for the business. The perks Google employees receive are, for instance: free food and drinks, onsite gyms, concierge services, free massages and more. However, Cappelli (2014) seems to suggest that many of those benefits make it much easier for the employee to spend more time at work than anywhere else.

Bakker (2016) analyses how Google influenced its employees' behavior at work to inspire more healthy choices. The author suggests that providing employees with information is not enough to inspire action. This is why researchers have done an experiment in Google and changed some details of the food and snack options available. It turned out that a few simple tricks (like distributing $m \& m$ 's snacks in a small bag rather than from a dispenser into a big bowl) can strongly influence choices Google employees made. At the same time, Bakker (2016) stresses that even when introducing such changes at a company level, one must always be mindful of leaving other options to choose from. Re-designing the whole menu and changing all the 
previously available snacks in a heartbeat can create a feel of mistrust and dissatisfaction among the employees.

\section{Worksite Wellness Future Opportunities}

Evaluation of the effectiveness of wellness programs entails the need to develop health programs in line with the health problems of employees. These problems should be systematically investigated so that the organizational actions can come to full fruition.

Mortenson (2017) defines current shifts and changes in the wellness world. The author introduces the new rules of wellness. The approach for the future, according to Mortenson, will include: a comprehensive, integrated approach to health - the benefits will be integrated to best address holistic wellbeing; understanding the employee in holistic terms, not only in the terms of the skill set and know-how; customized, tailored approach towards each individual employee; rewarding employees for healthy choices and behaviours, not punishing them for lack thereof; integrating fitness and physical activity into the working day (on-site gyms etc.) as opposed to exercising during after-work time; integration of the wellness program with biometric screenings for the employee to build one approach to health; not only providing information about healthy lifestyles, but introducing coaching sessions and sharing available online resources, using varied communication channels (phone, email, text messages, live conversations etc.) Lindenberg (2014) has identified similar changes in worksite wellness programs. The author claims that the future of WWPs will be based on an individualized approach to each employee and his/her personal health needs allowing the best alignment between the health of the individual and the company.

Interestingly, Schwarzbach (2014) points out to an aspect of health, which does not seem to be as intensely addressed as other ones. Namely, sleeping. The author names the three components of good health - physical activity, nutrition and sleep - and point to the fact that the first two have gained 
much more attention than the latter. This presents a new opportunity for the worksite wellness programs.

\section{Conclusion and recommendations}

Companies operating currently on a very competitive market are aware of the growing demands of employees and the health consequences of these demands. Therefore, they are launching more and more programs for the well-being of employees. When they do so, they should take into account cultural considerations.

Although the concept of worksite wellness has originated in the United States and became globalized, wellness programs spread across the globe usually do not take into consideration cultural differences (The Future of Wellness at Work (Rep.), Global Wellness Institute, 2016). In a report by McCann company (The Truth About Wellness, 2013), cultural differences in the understanding of health have been investigated. For instance, there were some differences regarding what the most important components of maintaining future wellness are. The British and American respondents answered that exercise is the priority while Chinese and Japanese respondents stressed the function of nutrition. Turkish and Chinese prioritized being happy and positive in the maintaining of future wellness. There was also research conducted investigating the influence workplace relationships have on employee engagement and wellbeing among Australian and American employees (Brunetto et al., 2013). According to the results of their research, a model they created was much more accurate to predict the relationship in the group of Australian employees than the American. As indicated in numerous research in this article, if wellness programs are to be effective, they should be created with regard to the culturally conditioned expectations of the employees. 


\section{Bibliography}

Bens C. (2017), What is Workplace Wellness, Really?. Corporate Wellness Magazine, [online], Available: http://www.corporatewellnessmagazine.com/worksite-wellness/ workplace-wellness-really/ [dostęp: 21 marca 2017].

Bergbom, B. and Kinnunen, U. (2014) Immigrants and host nationals at work: Associations of co-worker relations with employee well-being. International Journal of Intercultural Relations, no 43, pp. 165-176.

Boddy, C.R. (2013) Corporate Psychopaths, Conflict, Employee Affective Well-Being and Counterproductive Work Behaviour. Journal of Business Ethics 121, 1, pp. 107-121.

Brunetto, Y. et al. (2013) The impact of workplace relationships on engagement, well-being, commitment and turnover for nurses in Australia and the USA. US National Library of Medicine, [online], Available: https://www.ncbi.nlm.nih.gov/pubmed/23651183 [14 March 2017].

Cappelli, P. (2014) Google Adds Benefits, Walmart Cuts Them; Oddly, the Logic Is the Same. Harvard Business Review, [online], Available: https://hbr.org/2014/11/googleadds-benefits-walmart-cuts-them-oddly-the-logic-is-the-same [27 March 2017].

Carlson, J. (2014) The Evolution of Workplace Wellness Programs. Baylor Business Review, 33(1).

Chance, Z., Dhar, R., Hatzis, M. and Bakker, M. (2016) How Google optimize Healthy Office Snacks. Harvard Business Review, [online], Available: https://hbr.org/2016/03/ how-google-uses-behavioral-economics-to-make-its-employees-healthier [12 March 2017]. 
Chen, T. et al. (2016) Effect of Workplace Counselling Interventions Launched by Workplace Health Promotion and Tobacco Control Centers in Taiwan: An Evaluation Based on the Ottawa Charter. Plos Journals, [online], Available: http://journals.plos. org/plosone/article?id=10.1371/journal.pone.0150710 [17 March 2017].

Dailey, S.L. and Zhu, Y. (2016) Communicating Health at Work: Organizational Wellness Programs as Identity Bridges. Health Communication, 32(3), pp. 261-268.

Dodge, R., Daly, A.P., Huyton, J. and Sanders, L.D. (2012) The challenge of defining wellbeing. International Journal of Wellbeing, 2(3), pp. 222-235.

Edmunds, S., Stephenso, S. and Clow, A. (2013) The effects of a physical activity intervention on employees in small and medium enterprises: A mixed methods study. IOS Press: Work, no 46, pp. 39-49.

Elia, J. and Rouse, M.J. (2016) Do Workplace Wellness Programs Work? Plans \& trusts, 34(5), pp. 12-17.

English Oxford Living Dictionary, [online], Available: https://en.oxforddictionaries. com/definition/health [14 February 2017].

Everyday Health INC. Global Wellness Institute (2016) Unlocking the Power of Company Caring (Rep.), [online], Available: https://www.globalwellnessinstitute.org/industry-research/ [23 March 2017].

Lavine, M. (2012) Exploring the Relationship between Corporate Social Performance and Work Meaningfulness. JCC, [online] http://www.ingentaconnect.com/content/glbj/ jcc/2012/00002012/00000046/art00005?crawler=true [10 March 2017].

Lindenberg, B. (2014) The Future of Workplace Wellness Programs. Plans \& trusts, pp. 8-10. 
Malleret, T. (2016) Workplace Wellness is now a Strategic Priority in the U.S, Global Wellness Institute, [online], Available: https://www.globalwellnessinstitute.org/global-wellness-institute-blog/2016/11/22/workplace-wellness-is-now-a-strategic-priority-in-theus?utm_source=Master\%2BList\&utm_campaign=0a8ef4b432-2016_11_22_GWI_Brief_A_B_ Test11_22_2016\&utm_medium=email\&utm_term=0_bbb41a322d-0a8ef4b432-69678261 [23 March 2017].

Malleret, T. (2017) Study: Reducing Depression \& Anxiety Would Have Bigger Impact than Eliminating Poverty, "Global Wellness Institute", [online], Available: https:// www.globalwellnessinstitute.org/global-wellness-institute-blog/2017/2/28/ study-reducing-depression-anxiety-would-have-bigger-impact-than-eliminating-poverty?utm_source=Global\%2BWellness\%2BInstitute\&utm_campaign=2be243fee9-EMAIL_CAMPAIGN_2017_02_28\&utm_medium=email\&utm_term=0_bbb41a322d-2be243fee9-69678261 [24 March 2017].

Mazur, B. and Mazur-Małek, M. (2017) Evaluating the effectiveness of worksite wellness program. International Journal of Contemporary Management [Współczesne Zarządzanie Kwartalnik Środowisk Naukowych i Liderów Biznesu], no 1, vol. 16, pp. 77-89.

McCann (2013) The Truth About Wellness (Rep.), McCann Truth Central.

Mehta, S. and Maheshwari, G.C. (2013) The consequence of Toxic Leadership on Employee Job Satisfaction and Organizational Commitment. The Journal Contemporary Management Research, 8(2), pp. 1-23.

Mellor, N. and Webster, J. (2013) Enablers and Challenges in implementing a comprehensive workplace health and well-being approach. International Journal of Workplace Health Management, 6(2), pp. 129-142. 
Mortenson, P. (2017) The New Rules of Wellness. Corporate Wellness Magazine, [online], Available: http://www.corporatewellnessmagazine.com/worksite-wellness/ the-new-rules-wellness/ [26 March 2017].

Preamble to the Constitution of the World Health Organization as adopted by the International Health Conference, New York, 19-22 June, 1946; signed on 22 July 1946 by the representatives of 61 States (Official Records of the World Health Organization, no. 2, p. 100) and entered into force on 7 April 1948.

Purcell, J. (2016) Employers Need to Recognize That Our Wellness Starts at Work. Harvard Business Review, [online], Available: https://hbr.org/2016/11/employers-needto-recognize-that-our-wellness-starts-at-work [21 March 2017].

Robroek, S.J., Vathorst, S.V., Hilhorst, M.T. and Burdorf, A. (2011) Moral issues in workplace health promotion. International Archives of Occupational and Environmental Health, 85(3), pp. 327-331.

Schwarzbach, K. (2014) Wakeup Call: Good Sleep is Good for Employees. Corporate Wellness Magazine, [online], Available: http://www.corporatewellnessmagazine.com/ column/wake-up-call-good-sleep-is-good-for-employees/ [4 April 2017].

Serxner, S. (2017) Reassessing Your Wellness Programs to Create A Culture of Health. Corporate Wellness Magazine, [online], Available: http://www.corporatewellnessmagazine.com/worksite-wellness/reassess-create-culture-of-health/ [27 March 2017].

Sinek, S. (2011) Simon Sinek: If You Don't Understand People, You Don't Understand Business (Foketux, Ed.), Youtube, [online], https://www.youtube.com/watch?v=8grVwcPZnuw [26 March 2017].

Sinek, S. (2012) Simon Sinek: Love Your Work (Creativemornings, Ed.), Youtube, [online], Available: https://www.youtube.com/watch?v=jDIZS4IQIQk [26 March 2017]. 
The Future of Wellness at Work (Rep.) (2016), "Global Wellness Institute", [online], Available: https://www.globalwellnessinstitute.org/industry-research/ [21 marca 2017].

Tylor, E. (1871) Primitive culture, London: John Murray.

Walsh, M., Dupre, K. and Arnold, K.A. (2014) Processes through Which Transformational Leaders Affect Employee Psychological Health. German Journal of Human Resource Management: Zeitschrift für Personalforschung, 28(1-2), pp. 162-172. 